\title{
C. S. LEWIS AND THE CHALLENGE OF ETHICS IN DIGITAL SOCIETY
}

This paper examines the idea that digital societies lack an ethical framework for understanding and mitigating the impact of digital technologies on human flourishing and the consequent diminishing of human agency. The authors examine how selected works of C.S. Lewis address man's moral responsibility while living in a developing society and call for a grounding in metaethical frameworks prior to any outcomes of applied ethics. Each of the authors contributes from his own field of expertise - Mahrik on nanoethics and Neal on digital media - while Lewis' writing corpus is the shared interest as well as the basis for their research. Writing and thinking from within a metaethical framework he terms the Tao, or natural law, Lewis offers an approach to the dehumanization of digital culture through his own approach to one of the oldest technologies: that of language. This offers the beginning of an infrastructure for thinking about and reacting to digital society in an ethical manner.

Keywords: C. S. Lewis, language, nanoethics, metaethics, digital society, responsibility, human dignity, dehumanization, natural law

\section{Introduction}

A main concern of this article is to understand what prevents us from creating ethical frameworks on which to build our digital culture and how we might begin to construct such frameworks in a way that values our humanity rather than dehumanizing us. We will examine how mass acceptance of digital technologies has occluded the purposes for which technologies exist and how these purposes are strongly anti-human. We then suggest how an ethical structure might begin to be built.

The term "digital technologies" is vague and imprecise and has ceased to have much meaning in the wider culture. Nearly every technology we engage with these days has some form of backend digitization, so we will confine our discussion to that portion of digital technologies that involve some kind of screen that we can interact with: a smartphone, computer, any type of tablet or television screen where we can access the Internet, apps or other media platforms. We will refer to them as screen technologies hereafter.

A number of thinkers have offered varying viewpoints on the diminishing of the human in the technological society; we will pull from Jacques Ellul, Marshall McLuhan, Sven Birkerts and others to offer insights where appropriate, but our primary concern will be with understanding C.S. Lewis's approach, through language, to an ethically responsible use of screen technologies.

\section{Ethical challenges of technology}

No one will argue about the ease with which screen technologies have deeply infiltrated our lives with barely a ripple of dissent or questioning. For those of us who are old enough to remember, the shift from analog to digital was welcomed as a breakthrough in convenience and efficiency. How quickly we adapted from our long-standing, long-form habits to this new ease. For screen technology to slide under the radar, as it were, and insinuate itself so steadfastly in our culture, there must be some bias that exists which prevents us from accurately thinking about it. Birkerts argues that the totality of technology in our lives has hampered us from having any point of purchase on the conversation and that because its operations are invisible, we believe them to be incapable of changing us or the world around us [1, p. 70].

On the other hand, McLuhan believed that every new technology is not simply a process of beneficial accretion, but that each reorders the culture as well as the sense ratios within the self without our realization [2, p. 31-32]. He believed that the content of any medium blinds us to the medium itself [2, p. 20]. McLuhan also reminds us that the extension of our beings by any new technology and the totality of the way it reorganizes life is too great for our sensory perceptions to accommodate, so as a defense we unconsciously become numb, what McLuhan terms narcosis, which leads to a loss of recognition of what has happened [2,

\footnotetext{
* ${ }^{1}$ Tibor Mahrik, ${ }^{2}$ Mark Neal

${ }^{1}$ Department of General and Applied Ethics, Faculty of Arts, Constantine the Philosopher University in Nitra, Slovakia

${ }^{2}$ Armagard Ltd Company and C.S. Lewis, Chicago, Illinois, USA

E-mail: tmahrik@ukf.sk
} 
p. 64]. Thus, we blindly acquiesce without knowledge of what we are doing.

Our susceptibility to propaganda is another reason why it is difficult for us to form ethical frameworks of any value in relation to screen technologies. Greenman, Schuchardt and Toly, writing on philosopher Jacque Elull's understanding of propaganda, describe its purpose as "integrating human beings into a dehumanized world, to adapt them to the technological society." It does this by "synthesizing contentment or distraction. . . by convincing people of the merits and virtues of their new milieu" [3, pp. 40-41]. Through intimate psychological and cultural knowledge and through deep data collection, propaganda seeks social and technological conformity through collective buy-in and action as a result of its message.

Van der Laan extends Ellul's explanation further by incorporating the twin manifestations of seduction and temptation into the propagandistic formula. The ultimate outcome is consumer capitalism. These two concepts are the grist through which the mill of propaganda continues to grind in our culture [4, p. 510]. What is of interest for us to note is that we are genuinely unaware of this process, especially as it occurs in the digital realm. Our screen technologies dictate our behaviors through advertising and marketing tactics, menu-driven interfaces, and a host of other silent and invisible methodologies. Think of what you see the next time you visit your Amazon account. Amazon seems to know all about your wants and desires and dangles them enticingly before you. But we don't see this as propaganda. We see it as convenience and ease. Because we remain unaware of propaganda at this level, we do not see the need for any framework of response.

McLuhan stated that only the artists in a culture are able to sidestep the main impact of any technological incursion and through their art provide models for facing the change rather than being steamrolled by it [2, pp. 95-96]. Birkerts, writing more than fifty years later, notes that "ours is a period strangely without show of artistic force" [1, p. 20]. We need a similar model, an art that will enable us to step outside of the narcosis inherent in screen technologies and propaganda and accurately assess and mitigate their impact. Otherwise we remain unaware of losses and the processes of dehumanization engendered by our media.

One of the primary losses we experience is that of agency. Birkerts points out that our human agency is "at every level overridden by scripted protocols," and gives an overreliance on GPS as an example of a loss of map-reading skill [1, p. 30]. As protocols take over and we cede the territory formerly occupied by a honed skill, we lose that much of what makes us human as well as strengthen our faith in technological solutionism [1, p. 36].

In attempting to understand what a loss of agency signifies, Birkerts muses on the existential differences between two hypothetical people sitting at a country bus stop. One has an unmediated experience of their environment. He stares across the fields; watches the tumbleweed drifting down the empty road. The other, say, has a smartphone. The former is existentially in a different position; he is himself, interacting with his surroundings, which are intrinsically themselves. The latter is engaged in a vast array of potentialities and connections via a highly mediated experience; he has ceded some of his agency to a device to perform functions he could otherwise do for himself [1, pp. 37-38]. In this scenario, loss of agency could be construed as a loss of incarnational reality, of a becoming visible in the world. Rather, it is blending in and becoming invisible. This invisibility is precisely why we need an ethical framework or art for our screen technologies that will re-humanize us.

A second loss is the devaluation of language. Both van der Laan and Greenman et al. note that language was of primary importance to Ellul; it is essentially what makes us human. Gladney notes that Ellul blamed what he called "the humiliation of the word" on the precedence of the image in the technical society as the preferred means of communication in culture, thereby emptying language of much of its nuance and meaning [5]. Van der Laan calls this emptying "plastic language," words that have been divested of their moral overtones and made to be interchangeable and to apply to any situation. This eliminates complexity and makes language more efficient, a key component of a technical society [4, pp. 350-351]. This shift of language from precision to generality was also corroborated by Lewis, who writes of ramification in language, the decay in meanings of a word that can lead to the loss of the original meaning. If this process continues, Lewis notes, the word eventually dies; it ceases to have any meaning [6, p. 9]. Similarly, van der Laan remarks of this trajectory that when a word means everything, it means nothing. Yet this is how language functions in a technologized society [7, p. 351]. If Ellul is correct, and language is the fount, as it were, of our humanity, then its devaluation would lead to a certain degree of dehumanization and a loss of human flourishing. As language loses complexity and nuance, it loses its ability to describe the human situation, which is nothing if not complex. Kondrla and Repar write about "the complexity of our responsibility" [8] when dealing with the need to understand moral dimension of our actions. When efficiency is the standard of the screen technology culture, language must also become efficient. When our language becomes efficient, it becomes debased and we are more prone to fall victim to propaganda.

\section{C. S. Lewis: rhetoric, language and the Tao}

C. S. Lewis appreciated how technology, propaganda and the devolution of language dehumanized man. His careful approach to language forms a basis on which to build a framework of response to the screen technologies that enmesh us in propaganda and attenuate our agency. To effectively appreciate Lewis's approach and add shading to our art, we will frame our discussion by briefly examining how rhetoric should rightly function and how it can be manipulated for propagandistic purposes. 
Root and Neal have described the rhetorical consequences of debased language in their examination of Richard Weaver's The Ethics of Rhetoric. Firstly, rhetoric aspires to the highest good or ultimate term. Rhetorical terms can be likened to links in a chain connected to the master link (or ultimate term), or "the good," which subsequently transfers its influences down the chain. Weaver labels these ultimate terms "god terms" [9, p. 124].

For example, justice or progress might be god terms, the highest good toward which a rhetorician is trying to influence an audience or the highest terms valued by a society. Today, technology is one of our god terms. Negative connotations are not necessarily attached to god terms; however, they may tend to be viewed blindly and may lead to groupthink. Groupthink produces an illusion of invulnerability and a loss of independent thinking. Consider how digital technologies and technological solutionism are seen as a sort of savior in our time. There are few dissenting voices questioning whether we need more devices or apps or solutions. Our narcosis ensures that we blindly accept these changes [9, p. 124].

Weaver also identifies another type of ultimate term, "charismatic terms." These terms possess no derivation or referents; they have broken free of their place in the rhetorical chain. Weaver suggests they are the result of a "spontaneous general will" [9, pp. 124-125]. Examples of this are freedom or democracy. Charismatic terms can, of course, have their authority forced upon them. This is the intentional forcing of terms lower in a rhetorical chain into ultimate positions. This is certainly the case when the mill of propaganda is in full operation.

Political discourse is riddled with these terms. Weaver suggests that truncated terms like FBI, FDIC, NPA, or NEP represent governmental efforts to force charismatic authority on them. Once words become abstractions by being truncated, they lose any correlation to rational rhetoric because they divorce the word from meaning and import. During the second World War, terms such as defense and war effort became charismatic terms in the United States. Such terms often become ultimate in times of crisis, but they still serve to manipulate and control the way they reflect about any given situation. Importantly, charismatic terms function in such a way that all of life can be defined in relation to them. Here we see an echo of van der Laan: plastic language is language that can be applied to anything and everything and thus means nothing. Charismatic terms are forced into ultimate positions intentionally in order manipulate. Any group determined to have control, Weaver states, will want to appropriate the sources of charismatic authority [9, p. 125]. History offers many examples: The Third Reich, totalitarian regimes, the list goes on.

Having thus framed our discussion, we now turn to C.S. Lewis's work Abolition of Man. Here Lewis attempts to explain the natural outworking on human beings of language that has been stripped of all value judgements by divorcing facts from feelings. It examines how the dissemination of essentially base rhetoric through something as simple as school textbooks can lead to a loss of value in language which in turn can lead to the loss of a framework for appropriately living in the world. Lacking a framework for our lives in general and not possessing what Lewis calls 'ordinate responses' to the world around us, we won't know how to appropriately respond to our screen technologies. This leaves us open and vulnerable to propaganda, to being controlled and manipulated without our knowledge by those Lewis calls the "conditioners" and without any ability to know either how to respond or that we should even have a response.

Lewis begins by examining a school textbook of the day written by two schoolmasters. By reading between the lines, he discovers two critical issues in this book: that any value statement about a particular issue is simply a statement about a person's feelings and that all such statements are unimportant. The authors do not disabuse their readers of this notion and so pave the way for the readers to perform this extension to all statements of value. Lewis [10, pp. 4-5] calls this activity 'debunking,' or the removal of whatever is between us and the true reality of anything. The natural trajectory for this starvation of sensibilities is to make the individual a far easier prey for the propagandist.

The schoolmasters have used a form of base rhetoric to create this scenario. They have not moved their pupils toward the highest good in the rhetorical chain. Indeed, they could not admit that there was a highest good, because this in itself is a value statement. Thus, the schoolmasters have implicitly taught the pupils that there is no ultimate standard of objective value.

Lewis points out however [10, pp. 14-16], that until recent times, men believed that the universe elicited responses from us that could be either appropriate or inappropriate. Thinkers from Augustine to Aristotle have believed that the goal of education is to train pupils in appropriate responses to the world around them. Thus, if the pupil develops just sentiments, his responses to the world around him will be appropriate.

Now Lewis [10, pp. 18-25] begins to develop his metaethical framework. Borrowing from the Tao of the Chinese to encompass this conception in all its religious and philosophical forms, he sets forth a doctrine of objective value, what he elsewhere calls natural law or the law of human nature. Continuing his argument, something that is either reasonable or unreasonable, appropriate or inappropriate, must be so because there is a standard that exists independently of it. This standard that points to something beyond the thing in question is what Lewis's schoolmasters avoid. To be in opposition to this standard is to regard all sentiments as non-rational. Thus, sentiments are either to be removed, or to be manipulated in others for reasons known only to the manipulators. Education along these lines becomes conditioning, or propaganda. Thus, trained emotions are a vital part of Lewis's framework because they mediate between mere appetite and intellect, neither of which is sufficient on its own. It was all there in the beginning, in Plato. Like the metaphor of the rightly ordered city where the guardians rule the producers or craftsmen through the auxiliaries, intellect rules the appetites 
through the sentiment in the rightly ordered man. Once man has been stripped of his sentiment, Lewis writes [10, p. 27] that our society then clamors for the sorts of qualities and actions that an education along these lines has made impossible. He writes that "we remove the organ and demand the function."

Lewis proceeds to show how those who operate outside of the Tao will never be able to find a new system of values after they have debunked everything else. For him, the Tao is the source of all value judgements. Thus, ideologies and propaganda are concepts that have been taken from the Tao and swollen out of proportion; this is also an example of Weaver's charismatic authority, where rhetorical terms have been forced out of their original positions into ultimate terms for use of control and propaganda. Valco points to the prevalent tendency in most developed Western economies, where human individuality and personhood seem to be "lulled by the omnipresent slogans of freedom, especially in its economic and moral senses" that lead people away from spiritual integrity and mature moral responsibilities [11].

Finally, Lewis [10, pp. 56-57] shows the outworking of this lack of framework in society in general and to applied science in particular, or what he calls "man's conquest over nature." As he explores this theme, he explains that man's conquest over nature is really the power of some men over other men. In the quest to make man ever more efficient, Lewis writes "if any one age really attains, by eugenics and scientific education, the power to make its descendants what it pleases, all men who live after it are the patients of that power. They are weaker, not stronger: for though we may have put wonderful machines in their hands we have preordained how they are to use them." This is the point at which we want to arrive. If, as Lewis suggests, our society has adapted a stance outside of the Tao and apart from any objective value, then that society lacks a framework with which to appropriately use its technologies. Not only does it lack a framework, but because it has been educated and conditioned to remove value judgements from language, it no longer has the capacity to recognize the need for a framework or to possess a language to create such a framework.

Without this capacity, we fall prey to McLuhan's narcosis and Ellul's cycle of propaganda. We are further incapacitated by the paucity of our language as it becomes increasingly efficient and mirrors the "advances" of a technological society. We have been lulled into an enchanted sleep and we function at the beckon of our enchanter. Ellul developed his ethics of technology to call the sleeper to awake and to spur people to an awareness of the dehumanizing effects of technology [3, p. 124]. In his passionate critique of modern technological tyranny Ellul also composed a list of "76 Reasonable Questions to Ask about Any Technology", where he addressed ecological, social, practical, moral, ethical, vocational, political, aesthetic and metaphysical considerations [12]. Lewis also notes that we "have need of the strongest spell that can be found to wake us from the evil enchantment of worldliness which has been laid upon us for nearly a hundred years” [13, p. 29]. Both call for a metaethical structure for appropriately responding to the world.

Though our culture continues to embrace a language which is not only debased, but lacks objective value and meaning, Lewis calls us to step back, to implement the historical imagination and remember the world as it was for thousands of years, governed by the moral framework of the Tao. Unless we possess a system of objective value, we cannot properly understand how to respond to our technologies; our responses to them will not be ordinate based on the thing they are, but merely conformist based on the thing society has shown them to be. By eliminating value judgements and attempting to delve deeper to the "real" that we believe underlies them, we find that even there we cannot eliminate the Tao. Only by completely denying our humanity can we step outside of this framework and so become inhuman.

To realign the self with the way of the Tao is the first step toward creating an ethical framework; this will take a forceful act of our will and a rejection of the notion that value judgements are to be shunned. Lewis offers us a path, rooted in the Tao, through a right understanding of and relationship with language.

\section{Assembling the framework: humans and the impact of language}

Language is itself a technology, so an appropriate response to it can mirror an appropriate response to our screen technologies. The comparison is appropriate because both are systems of communication and both contain and utilize language.

During his life, Lewis saw imaginative decay around him: a loss of care about the past, about language and about understanding literature. He had a keen sense of responsibility to language. This is why much of his literary criticism was written; to help people recapture the imaginative wonder of the worlds he inhabited when reading certain books and authors.

We would like to briefly examine two components of Lewis's understanding of the technology of language that will function as strategies which can enable a more appropriate engagement with screen technologies. To begin, we will need to make a distinction between kinds of readers, as defined by Lewis [14, pp. 2-9]. He writes that there are three kinds of readers who misunderstand an old text when they read it. The first misunderstand it brilliantly, jumping in wholeheartedly, making their best guesses and applying their best knowledge to it. The second class simply does not care. They bring their current worldview to an old text without any thought that they won't actually be reading the book as it was originally written. The third is the wise reader; he cares to discover the original meanings of words so that he can read the text as it was written.

Similarly, there are three classes of users of screen technologies. The first embrace it as a way of life, to create ease and additional opportunities. The second, the dullard, is ambivalent. The tools 
available are simply a means to an end. The third is the questioner, the one who seeks to understand the implications of technologies and how to live in right relation through them. It is to the third user of screen technology that we primarily write.

Armed with these distinctions, we can now provide our questioner with two strategies for approaching screen technologies. First is a historical understanding. We mentioned the use of the historical imagination earlier; Lewis [15, p. 202] writes of the blindness of the twentieth (we can extend this into the twentyfirst) century and how the only palliative is to keep the clean sea breeze of the centuries blowing through our minds. A historical approach asks about the original intended use of a word or concept to grasp the original text more fully. The reader attempts to understand the history of thought and sentiment that underlies the words that he might get a fuller picture of the time in which it is written. He attempts to shed his modern conceptions and don historical ones. Lewis notes that intelligence is not enough in this case; we need knowledge [14, pp. 2-4].

Similarly, the questioner of screen technologies will begin by understanding the history of media, the original and intended use of any given tool and the trajectory of that tool's incursion into society. In so doing, he will more readily assess with accuracy the current situation and begin to ask the right questions. Media theorist Neil Postman believed that students should be taught the history of technology in order to "understand the relationship between our technics and our social and psychic worlds, so that they may begin informed conversations about where technology is taking us and how" [16, p. 198].

The second strategy is a felt responsibility and action toward language. Lewis [14, pp. 7-8] describes the conditions that lead "to verbicide", or the murder of a word, as an example of why we should care to shoulder this responsibility. Firstly, inflation: words like awesome for "great" awfully for "very," and so on. Secondly is what Lewis calls verbiage. This is a use of words that promise something without delivering on the promise. Lewis gives the example of "significant" as a word that doesn't deliver on its promise as we are rarely told what a thing is significant of, only that it is significant. The third is appropriating language for its selling quality or for political or other purposes. This is base rhetoric and propaganda. The fourth and final cause is the tendency of language to become more and more evaluative and less and less descriptive. Everyone is eager to express their approval or disapproval of something; few will agree to simply describe it. Thus, reaction is preferred over reflection and language suffers decay. We find this tendency to be especially prevalent on social networking sites.

The questioner of screen technologies can take these four causes of verbicide and translate them into four ways to appropriately respond. Each shows a way in which language is eroded and loses power. Similarly, we can apply this to the ways in which our screen technologies erode us as human beings. Most obviously, they erode our language, as pointed out earlier, through the technological society's insatiable desire for efficiency. As Ellul and others have suggested, our language is what fundamentally makes us human. Therefore, a literal attention to language in the way Lewis suggests is a cut against the tide pull of the technologized society. We must resolve ourselves to not committing verbicide in our written or spoken language. In fact, the language component is so important that Ellul went so far as to say that discourse and conversation in relationship is our main strategy against the juggernaut of technology and we most effectively are opposed to its values when we engage in this way.

Both Lewis and Ellul agree that we will never stop the advances of technology, but that we can make a difference in our own spheres, however small or large they may be. Our visible-ness or incarnation, our humanity, in the world is made most apparent when we speak and engage with language in genuine relationship [3, p. 46]. Situated squarely within the Tao, we can understand how these strategies outlined by Lewis help to place us in proper relation to our screen technologies; to understand both the things they are and the things we are. In this work, we begin to wake up from our enchantment. In addition, we need to implement here that "modern science has rejected the Cartesian way of thinking with its mechanistic dualism" [17, p. 91] which makes the issue more complex.

\section{Nanoethics as an interdisciplinary challenge}

Nanotechnology is a new and fast developing technology which somehow penetrates and influences all areas of society and underlines the fact that science and society influence each other considering both its scientific and social needs. Nanoethics discusses the ethical issues associated with nanoscience and nanotechnology, such as the fairness of how the technology is distributed nationally and globally, the possibilities of changing human life, ability, personality, psychology, sociology etc., and fundamentally changing what a human being is [18, pp. 185-187]. We prefer the term nanoethics in this paper to another common phrase "ethics of nanotechnology" which some render as a less biased alternative. The argument behind this is the fact, that nanotechnology has an impact on society in a wider sense as legal and regulatory issues, research funding and priorities, equity, environment, health and safety, privacy and medicine. The ethical challenges in these different areas are identified, and the novelty of these challenges are analyzed currently.

According to Herzfeld [19, p. 18] when we are to deal with any new technology in order to embrace the maximum benefit and to minimize the risk it is useful to bring our ethical and technological considerations under the scrutiny of these three questions: Firstly, does technology provide tangible benefits to the community or individuals within that community? Secondly, does technology change the relationship of the individual to the community and if so, what kind of effects in moral terms might it bring? Thirdly, 
does technology change the nature of the community itself - again in terms of such virtues as solidarity, face to face communication, cultural identity etc.? In tune with C. S. Lewis also Winograd and Flores [20] underline the importance of language and relationship though discussing about AI phenomenon. Discourse is not simply just the passing of information, rather it is essentially a social activity. Thence to be human means to enter into commitments "through speaking and listening" otherwise "...we are acting in a less than fully human way, and we are not fully using language" and thence intelligence has meaning only in a true encounter. From another perspective, also Pavlikova tackles "the conflict between the individual and the state and the individual's moral responsibility" [21] within a social sensitivity framework that shows a direct connection to the language usage. We have to be aware that the power of modern technologies is not a singular power of an individual but rather a collective power of society [22].

Nanoethics also works with models and futurist concepts that are relevant to the promises emerging out of nanoscience and scientific projects that are funded by big corporations. According to Cameron, nature and our self-perception as human beings are expected to change, given the potential of nanotechnology, biotechnology, and cognitive science to bring about basic shifts in human nature along with the possibility, that "wholly new ethical principles will govern in areas of radical technological advance, such as the role of robots in human society etc" [23, p. 185]. Arguments for addressing such potential ethical issues are based on the fact, that nanotechnology is evolving with tremendous speed and it is unavoidable to foresee a huge impact on society that we are to experience in near future. The problem, however, is getting more complicated, as Keiper points to the uncertainty of the kind of nanotechnology's future impact we should anticipate. He argues [24] that we must even now begin to think through many different scenarios, which consequently bring the multidimensional complexity phenomenon on the table where an interdisciplinary approach and cross-cultural methodology is the only way to search for contingent answers. Since new technologies have always changed the world in some way or other and usually bring about unforeseen ethical dilemmas (the printing press, the internet, virtual reality), we need, therefore, to be over-prepared rather than under-prepared, even if that means elaborating hypothetical options and unlikely scenarios.

This will include collaboration across traditional disciplines and the recognition of the value of knowledge in areas other than our own. Interdisciplinary cooperation can enhance the process of better interpretation in terms of hermeneutics that could even open a new creative potential for science [25]. There are a variety of efforts to bring humanists and social scientists into close contact with natural scientists with the goal of developing constructive dialogues about the scientific work they being performed, in the field of nanotechnology especially at the major Centers for Nanotechnology in Society (CNS) and the University of California at Santa Barbara (UCSB) [23, p. 157]. Meekness, humility, transparency, sincerity and true interest in searching for objective truth are those values that stand as a basis for such endeavor. One of the options could be the further training of scientists in ethics as well as the training of ethicists in the field of nanoscience and technology equally. Such an example of an interdisciplinary program in ethics within EU context has been developed for biologists at the University of Lausanne in Switzerland, where throughout their education from BSc to $\mathrm{PhD}$ those biologists have one compulsory course in ethics each year [26]. Maybe interfaculty seminars could be a possible option in a Slovak context. That might enhance communication across the disciplinary boundaries and might trigger in the members of such group some form of collaborative projects in future.

\section{Conclusion}

From the speed of technological progress and its dissemination into all areas of society, it seems clear that to maintain a healthy response to these technologies and become the masters rather than the servants of our tools, an ethical response is called for. Whether it is an approach like Lewis's or a cross-cultural and multi-disciplinary collaboration, the important point is that conversation and dialogue around this topic is the crucial first step: a willingness to see the technological situation unequivocally; the good and bad taken together and examined through a multitude of lenses. It is language-and by extension-conversation that makes us truly human, so beginning here seems a fitting way to understand and promote human flourishing in the technological society.

\section{Acknowledgement}

This submission was created as part of a research assignment for the KEGA 044UKF-4/2016 grant: "Nanoethics - education tools formation: e-book and web platform.”

\section{References}

[1] BIRKERTS, S.: Changing the Subject: Art and Attention in the Internet Age. Graywolf Press, Minneapolis, 2015.

[2] MCLUHAN, M.: Understanding Media: The Extention of Man. Gingko Press, Berkeley, 2003.

[3] GREENMAN, J. P., SCHUCHARDT, R. M., Toly, N. J.: Understanding Jacques Ellul. Cascade Books, Eugene, 2012. 
[4] VAN DER LAAN, J. M.: Temptation and Seduction in the Technological Milieu. Bulletin of Science, Technology and Society, 24(6), 509-514, 2004.

[5] GLADNEY, G.: Technologizing of the Word: Toward a Theoretical and Ethical Understanding. Journal of Mass Media Ethics, 6(2), p. 101, 1991.

[6] LEWIS, C. S.: Studies in Words. Cambridge University Press, London, 2013.

[7] VAN DER LAAN, J. M.: Plastic Words: Words without Meaning. Bulletin of Science, Technology and Society, 21(5), 349-353, 2001.

[8] KONDRLA, P., REPAR, P.: Ontological Consequences of the Ethics of Technology. Communications - Scientific Letters of the University of Zilina, 19(1), 19-24, 2017; KONDRLA, P., TOROK, L.: Objective Faith and Weak Truth. European Journal of Science and Theology, 13(1), 79-86, 2017.

[9] ROOT, J., NEAL, M.: The Surprising Imagination of C.S. Lewis. Abingdon Press, Nashville, 2015.

[10] LEWIS, C. S.: The Abolition of Man. HarperCollins, New York, 2001.

[11] VALCO, M.: Rethinking the Role of Kierkegaard's "Authentic Individual" in Liberal Capitalist Democracies Today. European Journal of Science and Theology, 11(5), 129-139, 2015. For more on this topic see also: KRALIK, R.: Kierkegaard's Interpretation of Faith. XLinguae, 10(3), 37-44, 2017; LESKOVA, A., VALCO, M.: Identity of adolescents and its Dimensions in the Relation to Mass media: Philosophical and Ethical Reflections. XLinguae, 10(3), 324-332, June 2017; PAVLIKOVA, M.: Kierkegaard's Understanding of Man and Society. XLinguae, 11(1), 323-331, 2018; TAVILLA, I., KRALIK, R., MARTIN, J. G.: A Brief Recollection of Kierkegaard's Testimony on Reformation 500th Anniversary. XLinguae, 11(1), 354-362, 2018; MARTIN, J. G., PAVLIKOVA, M., TAVILLA, I.: Johannes the Seducer's Diary or the Seduced Kierkegaard's Diary. XLinguae, 11(2), 320-322, 2018; ZALEC, B.: Kierkegaard, Love as Duty and Sacrifice/Kierkegaard, ljubezen kot dolznost in zrtvovanje (in Slovenian). Bogoslovni vestnik, 76(2), 277-292, 2016.

[12] Online. Available: http://www.thewords.com/articles/ellul76quest.htm.

[13] LEWIS, C. S.: Mere Christianity. HarperCollins Publishers, New York, 2015.

[14] LEWIS, C. S.: Studies in Words. Cambridge University Press, London, 2013.

[15] LEWIS, C. S.: God in the Dock: Essays on Theology and Ethics. William B. Eerdmans, Grand Rapids, 1970.

[16] POSTMAN, N.: Technopoly: The Surrender of Culture to Technology. Vintage Books, New York, 1993.

[17] VALCO, M., BOEHME, A. J.: Christian Faith and Science - Can Science Enhance Theology? European Journal of Science and Theology, 13(3), 89-97, 2017.

[18] RASMUSSEN, A. J., EBBESEN, M., ANDERSEN, S.: Nanoethics - A Collaboration across Disciplines. Nanoethics, 6(3), 185193, 2012.

[19] HERZFELD, N.: Technology and Religion - Remaining Human in a Co-Created World. Templeton Press, Passadena, 2009.

[20] WINOGRAD, T., FLORES, F.: Understanding Computers and Cognition: A New Foundation for Design. Addison-Wesley Professional, Boston, 68-71, 1987.

[21] PAVLIKOVA, M.: Reading Auden as a Resource for Existential Reflection in a Society with Technocratic and Hedonistic Tendencies. Communications - Scientific Letters of the University of Zilina, 19(1), 39-43, 2017.

[22] TURCAN, C.: Hans Jonas' Ethics of Technology: Risks of Technological Society. Communications - Scientific Letters of the University of Zilina, 19(1), 35-38, 2017. Also: AMBROZY, M., VALCO, M., BHATTARAI, S.: The Ethical Aspect of Scientific Interest in Selected Physical Theories. Communications - Scientific Letters of the University of Zilina, 19(4), 79-84, 2017.

[23] GORDIJN, B., CUTTER, A. M.: In Pursuit of Nanoethics. Springer, New York, 2014.

[24] KEIPER, A.: Nanoethics as a Discipline? The New Atlantis, 16(Spring), 55-67, 2007.

[25] VODICAR, J.: Ethics and Natural Science through Paul Ricoeur's Hermeneutics. Communications - Scientific Letters of the University of Zilina, 19(1), 59-63, 2017. See also: AMBROZY, M., KRALIK, R., MARTIN, J. G. Determinism vs Freedom: Some Ethics-Social Implications. XLinguae, 10(4), 48-57, 2017; KRALIK, R., ROUBALOVA, M., LENOVSKY, L., TUSKA, T., VUKSIC, K. S.: Taanit Bechorim (Fast of the First-born) in Rabbinic Judaism. XLinguae, 11(2), 17-23, 2018; VALCO, M., STURAK, P.: The 'Relational Self': Philosophical-Religious Reflections in Anthropology and Personalism. XLinguae, 11(1XL), 289-299, 2018.

[26] DUBOCHET, J.: Citizen Biologists. The Lausanne Experience. EMBO Rep., 9(1), 5-9, 2008 